\title{
Prediction of Seawater Intrusion in Laizhou Bay Area under Groundwater Pumping Activities
}

\author{
Xiankui Zeng, Dong Wang*, Jichun Wu \\ Department of Hydrosciences, School of Earth Sciences and Engineering, Nanjing University, Nanjing, 210046, \\ China

\section{人类活动影响下莱州湾地区海咸水入侵预测分析} \\ 曾献奎, 王栋*, 吴吉春 \\ 南京大学地球科学与工程学院水科学系, 210046 , 江苏南京
}

\begin{abstract}
With the rapid development of society and economy in China, the demand for water resource is increasing with industry and agriculture activities. Due to the excessive exploitation of groundwater resource, and global climate change, the seawater intrusion had arisen at some coastal areas in China. In addition, the sustainable developments of local society, economy, ecology and environment are influenced by the harms caused by seawater intrusion. In this study, a typical seawater intrusion area in Laizhou Bay is used, and the numerical simulation model is constructed by using the code SEAWAT4. The temporal and spatial characteristics of the development of seawater intrusion is analyzed by considering two scenarios, one is the groundwater pumping keeps at current level, the other is the groundwater pumping increases by $50 \%$. Based on the prediction results, some prevention and treatment measurements have been proposed for current seawater intrusion.
\end{abstract}

Keywords: Seawater intrusion; Groundwater; Numerical simulation; Prediction

\section{摘要}

随着我国社会经济的快速发展, 对水资源的需求 量日益加剧, 我国沿海地区由于过量开采地下水, 以 及气候变化等原因, 导致不同程度的出现了海咸水入 侵问题, 影响了当地社会经济及生态环境的可持续发 展。本文以莱州湾某典型海咸水入侵区为例, 基于
SEAWAT 程序建立了海咸水入侵数值模拟模型, 考 虑在不同的地下水开采条件下, 对研究区内海咸水入 侵演化的时空分布特征进行分析与预测。根据海咸水 入侵的数值模拟分析结果, 结合研究区自然地质与社 会环境条件, 提出研究区海咸水入侵预防与治理措 施。

关键词: 海水入侵; 地下水; 数值模拟; 预测分析

\section{1. 引言}

近年来, 随着我国经济的快速发展和人民生活水平的 不断提高, 对水资源的需求量日益加剧, 我国沿海地 区由于过量开采地下水, 以及自然气候变化等原因, 导致不同程度的出现了海水入侵问题, 影响了当地社 会经济及生态环境的可持续发展。

莱州湾是中国最早发现海水入侵现象的沿海地 区之一。20世纪70年代中期, 为进行农业生产, 当地 农民兴起了使用机井灌溉的方式开发地下水资源, 随 着农业灌溉面积的扩大, 水井密度的增加, 开采量增 加, 某些水井水质长期变咸, 浇地后造成庄稼枯萎乃 至死亡。进入 80 年代, 沿海乡镇企业异军突起, 工矿 企业发展迅猛, 其水源地布局不合理, 多建在咸淡水 界限附近, 过量抽取地下水, 加剧了海水入侵的发展。 至 80 年代中期, 海水入侵已成为十分普遍的一种现 象。由于地下水无序的开发以及海水入侵被动的防 治, 造成海水入侵的加速和大面积发展, 山东省海水 入侵区由局部地段不断扩大成片, 目前海水入侵总面 积超过 $2000 \mathrm{~km}^{2}$, 海水入侵灾害引起了省级政府和中 央政府的高度重视 ${ }^{[1,2,3]}$ 。

莱州湾地区当前正面临着严峻的海水入侵及伴 随的生态环境问题。因此, 分析海水入侵的机理、认 识海水入侵的规律与特征, 通过数值模拟技术分析海 
Risk Analysis and Crisis Response in Big Data Era (RAC-16)

水入侵的时空分布特征, 分析在不同的人类活动强度 条件的海水入侵的范围与程度, 对于海水入侵的治理 与控制、地下水资源及生态环境的保护具有重要意义 $[4,5,6]$ 。本次研究选择莱州湾西部某一典型研究区, 考 虑在不同的地下水开条件下, 对研究区海水入侵的时 空分布特征进行分析与预测。根据海水入侵的数值模 拟分析结果, 结合研究区自然地质与社会环境条件, 提出研究区海水入侵预防治理的工程与非工程措施。

\section{2. 研究区概况}

\section{1. 研究区范围}

如图 1 所示, 研究区选择位于工作区的中部, 面积约 为 $1020 \mathrm{~km}^{2}$ 。研究范围的选择主要基于以下两个原 因, i) 研究区北部为海岸线, 南部接近工作区 (水 文地质调查工作) 边界, 范围适中, 能够代表工作区 海水入侵的基本特征; ii) 研究区大部分被水文地质 重点调查区所覆盖, 因此能够获得较丰富的研究资 料, 能够保证本次研究的顺利完成。

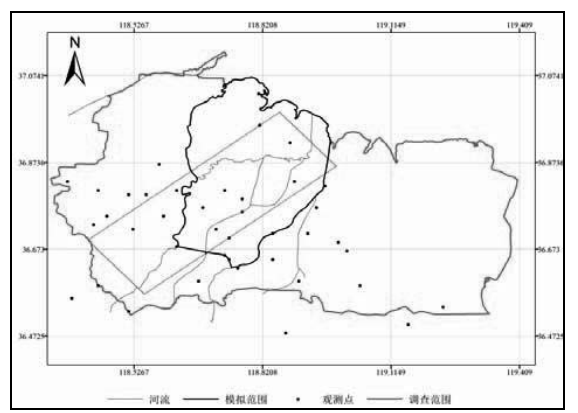

图 1 研究区范围示意图

\section{2. 水文地质参数分区}

研究区位于滨海平原区域, 该区域地下水主要赋存与 第四纪松散岩类孔隙介质中, 属于浅层淡水、潜水一 微承压水。从南至北, 含水砂层的岩性从中粗砂、砾 石等颗粒粗大的地层 (厚度一般 5-30m) 变化到为 粉砂、细砂及中砂（砂层厚 $10-30 \mathrm{~m}$ ), 富水性从强 一极强变化到中一强。

根据研究区内的前期水文地质调查资料, 图 2 所示为研究区水文地质参数分区示意图, 根据含水介 质的颗粒特征与沉积条件, 研究区被划分为 4 个子区 域, 各子区的水文地质参数值如表 1 所示。

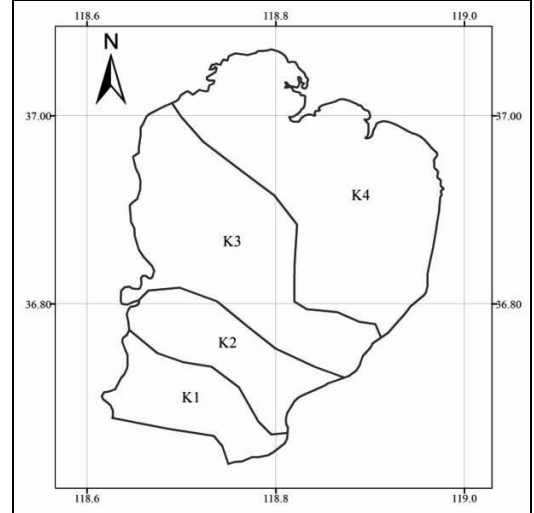

图 2 研究区水文地质参数分区图

表 1 研究区水文地质参数分区赋值

\begin{tabular}{|c|c|c|c|c|}
\hline \multirow{2}{*}{ 参数 } & \multicolumn{4}{|c|}{ 分区 } \\
\hline & 1 & 2 & 3 & 4 \\
\hline $\begin{array}{c}\text { 渗透系数 } \\
(\mathrm{m} / \mathrm{d})\end{array}$ & 15 & 12 & 8 & 6 \\
\hline $\begin{array}{c}\text { 储水率 } \\
(1 / \mathrm{m})\end{array}$ & 0.0002 & 0.0002 & 0.0003 & 0.0003 \\
\hline 给水度 & 0.25 & 0.25 & 0.2 & 0.2 \\
\hline $\begin{array}{c}\text { 纵向弥散度 } \\
(\mathrm{m})\end{array}$ & 15 & 12 & 10 & 8 \\
\hline $\begin{array}{c}\text { 横向弥散度 } \\
\text { (m) }\end{array}$ & 1.5 & 1.2 & 1 & 0.8 \\
\hline
\end{tabular}

\section{3. 边界条件及源汇项}

研究区的东部和西部边界均处理为河流边界条件, 河 流水位由上游至下游, 水位均匀递减, 且河床导水系 数保持固定。研究区北部为海岸带, 在此不考虑潮汐 等作用, 简化处理为定水头边界条件, 南部为一条贯 穿多处地下水位观测井的边界, 根据观测井的地下水 位动态观测资料, 将该边界处理为给定水头边界条 件。

研究区地下水源项主要包括降水、灌溉回渗、养 殖区回渗等, 汇项主要包括蒸发腾散作用、养殖区抽 采地下水、农业及居民生活开采等。其中，研究区表 层均匀接受降水的补给, 灌溉回渗均匀分布在农业 区, 养殖区对地下水进行分区开采, 总开采量约为 $40000 \mathrm{~m}^{3} / \mathrm{d}$ 。当前区内受人类活动影响显著的源汇项 为养殖区地下水开采量, 即为本次研究的目标。 
Risk Analysis and Crisis Response in Big Data Era (RAC-16)

\section{3. 海咸水入侵数值模拟}

本次研究采用SEAWAT4 模拟研究区三维海咸水入侵 过程。SEAWAT $4^{[7]}$ 是一款通用、源代码开放的海水 入侵模拟程序, 能够处理三维变密度、变粘滞度的多 类溶质的同时运移过程，且最近被广泛用于全球多个 地区的海水入侵模拟分析。

在空间上, 水平方向上网格空间离散单元的尺度 为 $200 \mathrm{~m} * 200 \mathrm{~m}$, 水平方向上被均匀离散为 3 层。在 时间上, 每个应力期长度设为 15 天, 每个应力期分 为 3 个时间步长。本次海水入侵数值模拟的研究对象 为地下水中的 $\mathrm{Cl}^{-}$浓度。将研究区北部边界海岸带处 理为定浓度边界条件 $\left.\left(\mathrm{C}^{-} \mathrm{Cl}^{-}\right)=19354 \mathrm{mg} / \mathrm{L}\right)$ 。淡水与 海水密度分别设置为 $1 \mathrm{~g} / \mathrm{L}$ 和 $1.025 \mathrm{~g} / \mathrm{L}$ 。

本次模拟考虑研究区内两种不同的情景模式, 分 别为: 1. 研究区内养殖区地下水开采量保持为当前 开采水平 $\left(40000 \mathrm{~m}^{3} / \mathrm{d}\right)$, 海平面保持当前水位; 2 . 养 殖区地下水开采量增加 $50 \%$ 至 $60000 \mathrm{~m}^{3} / \mathrm{d}$, 海平面保 持当前水位; 考虑在这两种情景模式下, 模拟期设为 10 年, 模拟起始时间为 2014 年 1 月 1 日, 一个月作 为一个应力期, 每个应力期分为 3 个时间段, 分析研 究区海水入侵的时空分布规律与特征。

\section{4. 结果与分析}

图 3-图 4 所示为情景 1 下, 研究区地下水 $\mathrm{Cl}$ 浓度分 布演化示意图。选择 $\mathrm{C}\left(\mathrm{Cl}^{-}\right)=250 \mathrm{mg} / \mathrm{L}$ 作为海水入侵 的标志。从中可以看出, 研究区海水入侵多年平均速 度约为 $28 \mathrm{~m} / \mathrm{a}$, 至模拟期为 10 年时, 入侵面积大约 为 $18 \mathrm{~km}^{2}$, 且入侵速度有逐渐降低趋于稳定的趋势。

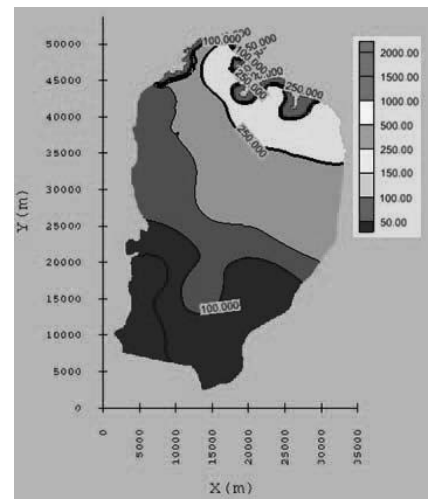

图 3 情景 1 下, 模拟期为 1 年时研究区 $\mathrm{Cl}^{-}$浓度分布 示意图

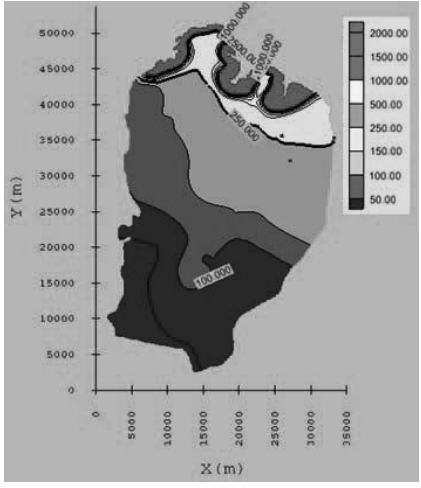

图 4 情景 1 下, 模拟期为 10 年时研究区 $\mathrm{Cl}^{-}$浓度分布 示意图

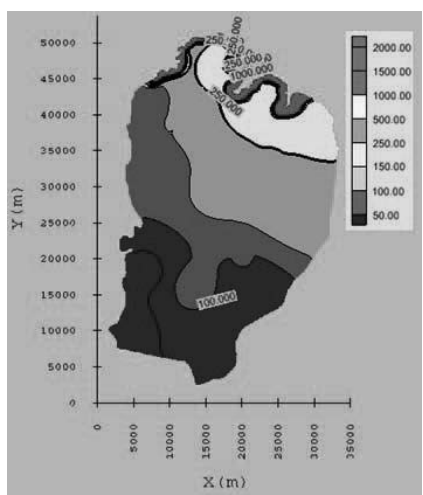

图 5 情景 2 下, 模拟期为 1 年时研究区 $\mathrm{Cl}^{-}$浓度分布 示意图

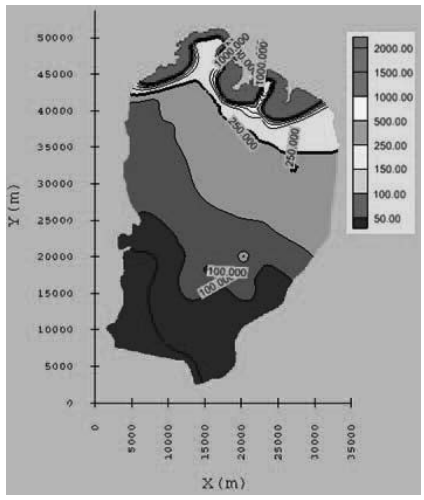

图 6 情景 2 下, 模拟期为 10 年时研究区 $\mathrm{Cl}^{-}$浓度分 布示意图 
Risk Analysis and Crisis Response in Big Data Era (RAC-16)

图 5-图 6 所示为情景 2 下, 研究区地下水 $\mathrm{Cl}^{-}$浓度分 布演化示意图。从中可以看出, 研究区海水入侵多年 平均速度约为 $35 \mathrm{~m} / \mathrm{a}$, 至模拟期为 10 年时, 入侵面 积大约为 $29 \mathrm{~km}^{2}$ 。

\section{5. 结论与建议}

本次海水入侵数值模拟的研究对象为水中的 $\mathrm{Cl}^{-}$浓 度。利用变密度溶质运移数值模拟程序SEAWAT, 建 立研究区海水入侵数值模拟模型。选择 2014 年 1 月 1 日为模拟预测起始时刻, 至模拟期为 10 年时 (2023 年 12 月 30 日), 情景 1 下, 入侵面积大约为 $18 \mathrm{~km}^{2}$ 。 情景 2 下, 入侵面积大约为 $29 \mathrm{~km}^{2}$ 。

海水入侵是由当地气候、水文、水文地质条件, 以及社会经济发展水平及产业结构、工农业生产条件 与方式等因素共同作用下的后果。为科学有效的控制 与治理海水入侵, 应当从工程措施与非工程措施两方 面协调防治, 如修建防潮海堤、修建拦蓄补源工程、 修建地下水库工程、淡水帷幕工程、人工回灌工程等 方式。

\section{Acknowledgements}

This study was supported by the National Basic Research Program (2013CB956503), National Natural Science Fund of China (No. 41302181, 41172207 and 51190091).

\section{致谢}

本研究得到了国家重点基础研究发展计划 (2013CB956503), 国家自然科学基金项目(41302181, $41172207,51190091)$ 的资助。

\section{6. 参考文献}

[1] 李福林, 莱州湾东岸滨海平原海水入侵的动态监 测与数值模拟研究. 2005, 中国海洋大学: 青岛.

[2] 韦政, 莱州湾海水入侵的时空演化特征研究. 2010，青岛科技大学：青岛．

[3] Li, S. J., Xie, Y. X., Cheng, X. T., et al., Utilization of Flood Simulation Technique in Urban Flood Warning - A Case Study on Fuzhou, Journal of Risk Analysis and Crisis Response, 2015, 5(2): 120-128.
[4] 山东省海洋与渔业厅, 2007 年山东省海洋环境质 量公报. 2007, 山东省海洋与渔业厅: 济南.

[5] 夏军, 李永,李福林,等 海平面上升对山东省滨海 地区海水入侵的影响. 人民黄河, 2013, 35(9): p. $1-7$.

[6] Zeng, X. K., Wu, J. C., Wang, D. et al., Assessing the pollution risk of a groundwater source field at western Laizhou Bay under seawater intrusion, Environmental research, 2016, 148: 586-594.

[7] Langevin, C.D., Thorne, D. T., Jr., Dausman, A. M., et al., SEAWAT Version 4: A Computer Program for Simulation of Multi-Species Solute and Heat Transport: U.S. Geological Survey Techniques and Methods Book 6, Chapter A22. 2007. 